\title{
Strategic Determinants of the Use of Development-Support Instruments in the Management of SMEs
}

\author{
Dr. Marek Matejun \\ Department of Management, Lodz University of Technology, Poland \\ E-mail:marek@matejun.com
}

\author{
Dr. Maciej Szczepanczyk \\ Department of Management Systems and Innovation, Lodz University of Technology, Poland \\ E-mail: maciej.szczepanczyk@p.lodz.pl
}

\section{Doi:10.5901/mjss.2013.v4n3p479}

\begin{abstract}
The development of small and medium-sized enterprises, which occurs under distinctive circumstances of resource shortages, is strongly determined by the ability to absorb the external instruments offered by commercial and non-commercial organizations supporting small business. Such instruments include those based on finance, capital, consulting, training, information, law, innovation or general business. The absorption of these instruments by SMEs depends on many factors of which strategic importance is given to intangible resources (knowledge and inter-organizational relations) as well as to skills and abilities (operational flexibility and the implementation of changes in an organization). With this in mind, the goal of the paper is to identify and assess the influence of these strategic factors on the use of development-support instruments by small and medium-sized enterprises. The study presents the author's own model of strategic resources and skills determining the use of development-support instruments in the management of SMEs. The goal of the paper was also pursued through empirical studies conducted on a sample of three-hundred small and medium-sized enterprises operating in the European Union.
\end{abstract}

Keywords: Business development, small and medium-sized enterprises, instruments supporting development, entrepreneurship.

\section{Introduction}

The development of small and medium-sized enterprises is connected with significant restrictions in resources - limited expert knowledge and a relatively small scope of market impact - alongside the pursuit of a high level of operating autonomy (Gilmore, Carson \& Grant, 2001; Ebert \& Griffin 2005). Due to their characteristics, these businesses are often unable to achieve their developmental goals using exclusively their own resources. Their growth therefore depends on the ability to absorb external development-support instruments (Smallbone \& Welter, 2009) offered by organizations that support small businesses.

The capacity to absorb these instruments depends on a given entity's attitude to development, and their use by SMEs relies on many factors of which strategic importance is given to intangible resources (knowledge and interorganizational relations) as well as to the key skills and abilities of operational flexibility and the implementation of changes in an organization. With this in mind, the goal of the paper is to identify and assess the influence of these strategic factors on the use of development-support instruments by small and medium-sized enterprises. The study includes a review of the international literature on the subject, as well as a presentation of the author's own model of the strategic resources and skills determining the use of development-support instruments in the management of SMEs. The goal of the paper was also pursued through empirical studies conducted on a sample of three-hundred small and medium-sized enterprises operating in the European Union. The quantitative studies employed cardinality tables, correlation analysis and multiple regression.

\section{Literature Review and Hypotheses}

Small and medium-sized enterprises (SMEs) play important economic and social roles in most countries around the world 
(Ayyagari, Beck, \& Demirgüç-Kunt 2007). Research conducted in different countries and regions (Anderson, Li, Harrison \& Robson 2003; Lukács 2005; Edmiston 2007; Ionica 2012; Ogbo \& Nwachukwu 2012) has revealed the special importance of SMEs in such areas as economic growth and the generation of GDP, increasing employment, reducing poverty, implementing innovations or promoting entrepreneurial spirit in society.

Because of the considerable internal diversity of the SME sector (Torrès \& Julien, 2005), a special social and economic role is assigned to small and medium-sized businesses that are geared for growth (Birch 1981; Davidsson, Lindmark \& Olofsson 1998; Nicholls-Nixon 2005; Henrekson, \& Johansson 2009). Such entities are referred to as gazelle companies, fast-growing businesses and entrepreneurial or innovative entities. They often pursue knowledge-based business (Gorman \& McCarthy 2006) in high-tech industries and on international markets and are involved in extensive R\&D cooperation (Hölzl 2009). Their operation is characterized by dynamic growth in revenues and employment and by the implementation of proactive and often anticipative qualitative changes that promote the construction of effective competitive advantage. Nevertheless, as D. Birch (1987) notes, these businesses are relatively scarce within the SME group.

On the other hand, the development of small and medium-sized enterprises is strongly limited by resource shortages and a relatively small scope of operation - as well as being determined by other characteristic features of the smallest business entities (Storey \& Greene 2010). Under these circumstances, special importance is given to the ability of SMEs to make use of external support, which is actualized in the form of the various instruments offered by the commercial, but primarily by the non-commercial (Albassam 2012), organizations that support small business and that are spread across the countries and regions of the globe (Harvie \& Lee 2002; Bossoutrot 2005; Acevedo \& Tan 2011; Qarri, Dumi \& Demo 2012; Dyson 2012; Wang \& Huang 2012). The major categories of external instruments supporting SME development include (Matejun 2013):

- financial instruments including various sources of external financing, such as credits, loans, leasing, factoring, EU grants, financial grants or guarantees

- capital-based instruments, e. g. the involvement of venture capital, business angels or other categories of individual or institutional investors

- consulting/training/information-related instruments aimed at the development of the knowledge, skills and competences of the company management and employees. These include training, courses, post-graduate studies and other means for expanding knowledge

- innovation-supporting instruments related to, e. g. technological audit or technology transfer

- general business-support instruments including, e. g. preferential access to office space and to the infrastructure used in business activities.

The tendency to absorb these growth and development instruments more frequently concerns entities that are highly growth-oriented. Another factor possibly determining their absorption is the stage of the company life cycle. According to numerous studies and theoretical models, a company's life cycle is associated with specific needs, as well as with specific challenges and barriers to growth (Felsenstein \& Schwartz 1993; Davidsson, Achtenhagen \& Naldi 2010). Taking into account the diversity of phase-based models of the company life cycle (Phelps, Adams \& Bessant 2007), the particular stages may be divided as follows (Matejun 2013):

- dynamic phases characterized by an active approach to business and by directing efforts to investment and development processes. These stages are expected to generate increased demand for the use of development-support instruments

- static phases characterized by more conservative and stable behavior, focusing on current operations and ensuring business continuity. In these stages, the demand for development-support instruments should be limited.

In particular phases, the demand for specific skills and resources changes (Churchill \& Lewis 1983; Adizes 1988) and certain problems appear that determine the further development of the company (Greiner 1972). Taking these considerations into account, the following research hypothesis was formulated:

H1: The absorption of instruments supporting development is significantly determined by the developmental orientation and phase of the life-cycle of SMEs, with the higher level of absorption being characteristic of highly growth-oriented companies in the dynamic phases of the life cycle.

The use of development-support instruments also depends on the individual activity of the given enterprise. These instruments are offered by institutions that support small businesses and therefore have to be actively obtained and employed by the company. This requires the activation of managerial initiatives aimed at monitoring and investigating the 
market environment, recognizing instruments that could provide adequate stimulation for particular developmental needs and identifying how these can be obtained and used as the company develops.

Obtaining and employing these instruments often imposes an adjustment to the specific requirements of the support institutions. In the case of commercial organizations, these requirements usually include meeting the entry criteria (e. g. for obtaining financial instruments) and meeting particular contractual requirements. However, the use of noncommercial instruments means meeting a much broader range of requirements, which usually concern positive social and economic impact (e. g. by creating and maintaining a specific number of new jobs, by implementing innovative solutions or by commercializing technologies).

The absorption of development-support instruments also requires SMEs to build various types of relationships and links with other entities. These relations are the basis both for obtaining support instruments (e. g. collaboration in preparing the required documents, feasibility studies and setting up a consortium) and for their use through direct cooperation with business-support institutions. Another factor determining the efficient use of development-support instruments is the ability to implement changes leading to organizational growth and progress. These changes go beyond their direct impact on SMEs and can, through the pursuit of broader social and economic goals, influence the environments in which they function.

Considering these characteristics of the absorption of SME development-support instruments, the capacity to use them efficiently depends primarily on possessing particular resources and on developing key abilities, which include:

1. Knowledge of the availability, terms of acquisition, benefits and possible threats of using various developmentsupport instruments. Nowadays, knowledge has become one of the key intangible assets of every organization. Researchers emphasize the growing importance of knowledge and organizational learning in the management of small and medium-sized enterprises (Dumi \& Maliqi 2011). They also point to the many challenges the small business must face in the process of implementing knowledge-management systems (Wong \& Aspinwall 2004), as well as to the high diversification in the approach of SMEs to the processes of organizational learning and knowledge generation (Rrustemi 2011).

2. Operational flexibility to meet the requirements set by support institutions, which is necessary for obtaining and using development-support instruments. High flexibility of operations is one of the fundamental and classic characteristics of SMEs (Storey 1994; Gupta \& Cawthorn 1996). This may concern various dimensions of a company, including steady state, operations, structure and strategy (Volberda 1996), and allows for a relatively easy adjustment to the changing environment.

3. Relations with the environment that are helpful in obtaining and using development-support instruments. Resource shortages compel SMEs to form various kinds of inter-organizational relationships. It should be emphasized that the inter-organizational cooperation undertaken by SMEs promotes the development of innovations (Zeng, Xie \& Tam 2010), helps achieve competitive advantage and allows for the efficient accumulation of knowledge (Adamik 2008).

4. Skills in implementing the developmental changes stimulated by the use of development-support instruments. It is stated in the literature that SMEs are not only more disposed than larger ones to introduce innovative developmental changes (Kaufmann \& Tödtling 2001), but also that their simpler structures and relatively smaller sizes enable easier implementation of new organizational solutions (McDonald \& Wiesner 1997).

This description suggests that the model's strategic resources and the skills determining the use of developmentsupport instruments directly correspond to the characteristics of small and medium-sized enterprises. Taking into account the above considerations, the following research hypothesis was formulated:

H2: The absorption of development-support instruments by SMEs is significantly determined by the involvement of resources, namely knowledge and inter-organizational relations, and by abilities, namely operational flexibility and the implementation of organizational changes.

\section{Research Methodology and the Characteristics of the Organizations and Respondents Surveyed}

The goal of the paper and verification of the study hypotheses was pursued through empirical research conducted on a sample of 300 small and medium-sized businesses from the European Union. The research method employed in the project was the survey method and the technique of questionnaires distributed directly to respondents. The research tool was a custom-designed questionnaire. The project was financed with funds from the Polish National Science Centre granted pursuant to decision no. DEC-2011/01/D/HS4/05894. This was a pilot study aimed at the preliminary verification of a trademark model of the strategic factors determining the use by small and medium-sized businesses of development- 
support instruments. For this reason, the study results are characterized by certain limitations and will be continued in the future, which is described in detail later on in the paper.

The research process involved a random selection of entities for the sample based on a population list provided by an external company that collaborated with the research team during the empirical work. The list included entities conforming to the uniform, formal definition of small and medium-sized enterprises according to the European Commission Recommendation (2003) and the European Commission Regulation (2004). The enterprises were operating in various sectors and industries and in various phases of the life cycle and had diverse attitudes to developmental processes and to the absorption of development-support instruments. Table 1 presents the detailed characteristics of the enterprises and respondents surveyed.

Sixty-seven percent of entities in the sample were small businesses (with an annual-average employment of 10-49 people) while $33 \%$ were medium-sized companies (employing 50-249 people). The enterprises studied were mostly privately-held companies $(60 \%)$ operating in services $(50 \%)$ or production $(49 \%)$ - mostly on a local or regional level $(62 \%)$. The respondents to the survey were composed of business owners (66\%) and managers representing enterprises (34\%). There were more male respondents than female, the respondents (both male and female) were concentrated in the 30-50 year-old bracket and the vast majority of both the women and the men had completed higher or secondary education.

Table 1. Characteristics of the enterprises and respondents surveyed

\begin{tabular}{|l|c|c|l|c|c|}
\hline Company size & Number & Percentage & Life-cycle stage & Number & Percentage \\
\hline Small & 201 & $67 \%$ & $3:$ Survival & 6 & $2 \%$ \\
\hline Medium & 99 & $33 \%$ & $4:$ Dynamic growth & 43 & $14 \%$ \\
\hline Sector: & Number & Percentage & $5:$ Separation and expansion & 15 & $5 \%$ \\
\hline Services & 150 & $50 \%$ & $6:$ Stabilization & 210 & $70 \%$ \\
\hline Production & 146 & $49 \%$ & $7:$ Revitalization & 17 & $6 \%$ \\
\hline Trade & 4 & $1 \%$ & $8:$ Decline & 8 & $3 \%$ \\
\hline Scope of operation: & Number & Percentage & Legal status: & Number & Percentage \\
\hline Local & 105 & $35 \%$ & Privately-held company & 179 & $60 \%$ \\
\hline Regional & 79 & $27 \%$ & Private partnership & 34 & $11 \%$ \\
\hline National & 67 & $22 \%$ & Limited liability company & 66 & $22 \%$ \\
\hline International & 49 & $16 \%$ & Joint-stock company & 8 & $3 \%$ \\
\hline & & & Other & 13 & $4 \%$ \\
\hline Respondent's gender & Number & Percentage & Respondent category & Number & Percentage \\
\hline Women & 122 & $41 \%$ & Business owners & 197 & $66 \%$ \\
\hline Men & 178 & $59 \%$ & Managers representing companies & 103 & $34 \%$ \\
\hline Respondents' education & Number & Percentage & Age of respondents & Number & Percentage \\
\hline Higher & 164 & $55 \%$ & 30 and younger & 14 & $5 \%$ \\
\hline Secondary & 123 & $41 \%$ & $31-40$ & 94 & $31 \%$ \\
\hline Vocational & 13 & $4 \%$ & $41-50$ & 88 & $29 \%$ \\
\hline
\end{tabular}

Source: Individual compilation based on study results.

\section{Results of the Empirical Research}

The first stage of the study consisted in the identification of the use of various development-support instruments by the companies surveyed. The instruments were grouped into five major categories: financial instruments, capital-based instruments, training and consulting instruments, innovative instruments and general business instruments. The respondents were asked about the scope of the use of these instruments in 2011. Fifty-three percent of the surveyed entities reported no use of any of the suggested development-support instruments. The other companies used mostly external sources of financing (39\%) and training, consulting and information-related instruments (25\%). The remaining categories were used much less extensively.

A very important part of the study concerned the attitude of the surveyed entities to the absorption of development-

${ }^{1}$ A single enterprise declared that it was in the early phase of 2 (emerging). Due to the very small number involved, this category was included in phase 3 (survival). 
support instruments in 2011. Due to the pilot nature of the research, a quantitative measure of absorption of development-support instruments was employed, which was based on the respondents' subjective assessments. The respondents specified the quantitative measure of absorption based on the suggested company descriptions. Their answers, and the adopted quantitative measure (rank) and level of absorption, are presented in Table 2.

The results show that the studied sample displays a strong relationship between the level of absorption and the number of categories of development-support instruments used. The strength of this relationship as measured with Cramér's $V$ is 0.68 . In addition, the calculation employing Spearman's rank correlation coefficient indicates a strong positive correlation between the characteristics under analysis $\left(r_{s}=0.893, p<.01\right.$.). This means that entities reporting higher degrees of absorption employ more categories of instruments supporting development. On the other hand, the chisquare test of independence shows that the level of absorption is significantly related to the number of categories of development-support instruments used: $X^{2}(4, N=300)=276.58, p<.0001$.

Table 2. Attitude of the surveyed entities to the absorption of development-support instruments

\begin{tabular}{|c|c|c|c|c|}
\hline Company description & $\begin{array}{l}\text { Quantitative } \\
\text { measure (rank) } \\
\text { of absorption }\end{array}$ & $\begin{array}{l}\text { Level of } \\
\text { absorption }\end{array}$ & $\begin{array}{l}\text { Number } \\
\text { of answers }\end{array}$ & Percentage \\
\hline $\begin{array}{l}\text { Enterprise not oriented to development, or pursuing } \\
\text { developmental goals using its own resources and } \\
\text { unwilling to use development-support instruments. }\end{array}$ & 1 & \multirow{2}{*}{ low } & 135 & $45 \%$ \\
\hline $\begin{array}{l}\text { Enterprise trying to obtain support and currently seeking } \\
\text { opportunities related to the use of development-support } \\
\text { instruments. }\end{array}$ & 2 & & 29 & $10 \%$ \\
\hline $\begin{array}{l}\text { Enterprise using selected instruments in support of } \\
\text { current operations - but not in direct relation to } \\
\text { developmental processes. }\end{array}$ & 3 & medium & 94 & $31 \%$ \\
\hline $\begin{array}{l}\text { Enterprise using development-support instruments but } \\
\text { focused on its own development and the resulting } \\
\text { advantages. }\end{array}$ & 4 & \multirow[b]{2}{*}{ high } & 31 & $10 \%$ \\
\hline $\begin{array}{l}\text { Enterprise trialing the use of development-support } \\
\text { instruments directly with developmental processes and } \\
\text { aware of the positive impact on the socio-economic } \\
\text { environment, e. g. through creating new jobs, } \\
\text { introducing new products and services, increasing } \\
\text { competitiveness and innovation, and other effects. }\end{array}$ & 5 & & 11 & $4 \%$ \\
\hline
\end{tabular}

Source: Individual compilation based on study results.

In order to use the absorption indicator as a dependent variable in the linear regression model, it was assumed that Likert-type scales (R. Likert 1932) may be used to a limited extent in parametric statistical procedures (Lubke \& Muthen, 2004; Göb, McCollin, \& Ramalhoto 2007). Such an approach, however, requires the adoption of specific premises, which concern e. g. equal spacing between the successive points of the scale and being aware of the limited possibilities of using the analysis results (Grace-Martin 2008). In this study, it is assumed that particular descriptions of enterprises corresponding to consecutive quantitative measures of absorption are equally separated from each other and form a regular continuum of absorption level. Moreover, taking into account the pilot nature of the research, the use of this scale in quantitative analyses seems justified - the more so as the results thus obtained are only an introduction to further, indepth quantitative studies that will employ more complex indicators for the identified dependent variable and for independent variables.

The independent variables in the analysis were four variables measured on a five-point Likert scale, which were used according to an analogical scale and procedure as in the case of the dependent variable (Absorption). These variables, in line with the above premises, are treated as quantitative variables. Furthermore, the set of independent variables was supplemented with two qualitative ones: a company's developmental orientation and phase of the life cycle. In the regression analysis, the first variable assumes the values 1, 2 or 3, and the second one is of a binary nature and takes the values 0 or 1 . The descriptive statistics for all the variables in the study are presented in Table 3.

Table 3. Descriptive statistics of the variables employed in the study 


\begin{tabular}{|c|c|c|c|c|c|c|c|c|}
\hline No & $\begin{array}{c}\text { Quantitative } \\
\text { variables }\end{array}$ & Type & Obs. & Mean & Mode & Min & Max & $\begin{array}{l}\text { Std. } \\
\text { Dev. }\end{array}$ \\
\hline 1 & Absorption & dependent & 300 & 2.18 & 1 & 1 & 5 & 1.216 \\
\hline 2 & Knowledge & independent & 300 & 2.63 & 3 & 1 & 5 & 0.999 \\
\hline 3 & Flexibility & independent & 300 & 2.58 & 2 & 1 & 5 & 0.952 \\
\hline 4 & Relations & independent & 300 & 2.66 & 3 & 1 & 5 & 1.062 \\
\hline 5 & Change & independent & 300 & 2.43 & 2 & 1 & 5 & 0.924 \\
\hline No & $\begin{array}{l}\text { Qualitative } \\
\text { variables }\end{array}$ & Type & Number & Percentage & \multicolumn{4}{|c|}{ Description } \\
\hline \multirow{3}{*}{6} & \multirow{3}{*}{$\begin{array}{l}\text { Developmental } \\
\text { orientation }\end{array}$} & \multirow{3}{*}{ independent } & 226 & $76 \%$ & \multicolumn{4}{|c|}{ low } \\
\hline & & & 46 & $15 \%$ & \multicolumn{4}{|c|}{ medium } \\
\hline & & & 28 & $9 \%$ & \multicolumn{4}{|c|}{ high } \\
\hline \multirow{2}{*}{7} & \multirow{2}{*}{$\begin{array}{l}\text { Phase of the life } \\
\text { cycle }\end{array}$} & \multirow{2}{*}{ independent } & 225 & $75 \%$ & \multicolumn{4}{|c|}{ static } \\
\hline & & & 75 & $25 \%$ & \multicolumn{4}{|c|}{ dynamic } \\
\hline
\end{tabular}

Source: Individual compilation based on study results.

To verify the research hypotheses, the linear regression analysis was performed within the framework of three theoretical models. In all cases, the absorption of development-support instruments was the dependent variable, whereas the independent ones were:

- in model no. 1: a company's developmental orientation and its current phase of the life cycle. The aim of this model was to verify hypothesis $\mathrm{H} 1$

- in model no. 2: factors identified in the course of theoretical considerations: knowledge, flexibility, relations and change. This model was used to verify hypothesis $\mathrm{H} 2$

- in model no. 3: all of the variables mentioned above. The aim of this model was to determine the effect of all of the identified variables on the level of absorption of development-support instruments in the entities studied.

Next, regression analysis was performed with respect to the individual theoretical models, assuming the continuity of quantitative variables and being aware of the limited usability of the study results. Model no. 1 included two predictors and explained $23.6 \%$ of the variability of the dependent variable (the adjusted R-squared amounted to $23.1 \%$ ). In the case of model no. 2, there was a significant growth in model matching (with adjusted R-squared amounting to 50.3\%). Including all of the independent variables in the model did not result in a significant, further increase in model matching, though the results indicated that model no. 3 most efficiently (54.3\%) accounted for the variability of the response variable (the adjusted R-squared for this model amounted to 53.4\%).

The variables occurring in models 1 and 2 considerably affected the value of the response variable, although the influence of flexibility on the absorption level in model no. 2 was identified as being of marginal importance. In the case of model no. 3, this variable did not affect the level of the response variable to any significant extent. The detailed results of the regression analysis are given in Table 4.

Table 4. Regression analysis concerning particular theoretical models

\begin{tabular}{|c|c|c|c|c|}
\hline Variable & $\begin{array}{c}\text { Model 1 } \\
\text { H1 }\end{array}$ & $\begin{array}{c}\text { Model 2 } \\
\text { H2 }\end{array}$ & $\begin{array}{c}\text { Model 3 } \\
\text { Full }\end{array}$ & $\begin{array}{c}\text { Model 3a } \\
\text { Full - optimized }\end{array}$ \\
\hline \multirow{2}{*}{ Developmental orientation } & $0.244^{\star}$ & & $0.164+$ & $0.159+$ \\
& $(0.109)$ & & $(0.86)$ & $(0.086)$ \\
\hline \multirow{2}{*}{ Phase of the life cycle } & $1.153^{\star \star}$ & & $0.425^{\star \star}$ & $0.451^{\star \star}$ \\
& $(0.162)$ & & $(0.138)$ & $(0.136)$ \\
\hline \multirow{2}{*}{ Knowledge } & & $0.370^{\star \star}$ & $0.366^{\star \star}$ & $0.393^{\star \star}$ \\
& & $(0.080)$ & $(0.77)$ & $(0.072)$ \\
\hline \multirow{2}{*}{ Flexibility } & & $0.149+$ & 0.087 & \\
& & $(0.90)$ & $(0.089)$ & $0.241^{\star \star}$ \\
\hline \multirow{2}{*}{ Relations } & & $0.228^{\star}$ & $0.216^{\star}$ & $(0.082)$ \\
\hline \multirow{2}{*}{ Change } & & $(0.88)$ & $(0.086)$ & $0.195^{\star}$ \\
& & $0.235^{\star}$ & $0.177^{\star}$ & $(0.087)$ \\
\hline \multirow{2}{*}{ Constant } & & $(0.90)$ & $(0.089)$ & $-0.293+$ \\
& $1.565^{\star \star}$ & $-0.353^{*}$ & $-0.337+$ & $(0.175)$ \\
\hline
\end{tabular}




\begin{tabular}{|c|c|c|c|c|}
\hline Observations & 300 & 300 & 300 & 300 \\
\hline R-squared & 0.236 & 0.510 & 0.543 & 0.542 \\
\hline Std. Error of the Estimate & 1.067 & 0.857 & 0.830 & 0.830 \\
\hline
\end{tabular}

Standard errors in parentheses.

+ significant at $10 \%$ level; * significant at $5 \%$ level; ${ }^{* \star}$ significant at $1 \%$ level.

Source: Individual compilation based on study results.

Introducing variables to model no. 3 through backward elimination resulted in the rejection of the flexibility variable $(p=$ $0.326,>$. 1). This led to the identification of the optimum model (Model $3 a$ ) that includes five predictors and accounts for $53.4 \%$ of dependent variable variability (the adjusted R-squared amounts to $53.4 \%$ )

\section{Discussion and Verification of the Research Hypotheses}

The research results demonstrated that the great majority of the entities surveyed (76\%) were businesses with a low orientation to development, while companies geared for growth were much scarcer in the sample. The results also revealed a poor level of use of development-support instruments in the management of the SMEs studied in 2011. More than half $(55 \%)$ of the companies reported only minor levels of absorption, which in effect meant almost no use of development-support instruments. Only $14 \%$ of enterprises absorbed these instruments to a high degree, which is associated with the use of development-support instruments for the stimulation of business-development processes and with the awareness of the impact this development has on changes in the company's environment. The dominant development-support instrument in 2011 in the group of entities that had made extensive use of them was the absorption of finance but, as shown in Table 5, training, consulting and information-related instruments also featured.

Table 5. The scope of use of development-support instruments in enterprises with high levels of support absorption in 2011

\begin{tabular}{|l|c|c|}
\hline \multicolumn{1}{|c|}{ Category of instruments } & Number & Percentage \\
\hline Financial instruments & 37 & $88 \%$ \\
\hline Training, consulting and information-related instruments & 34 & $81 \%$ \\
\hline General-business instruments & 14 & $33 \%$ \\
\hline Innovation-support instruments & 4 & $10 \%$ \\
\hline
\end{tabular}

Source: Individual compilation based on study results.

The next stage of the analysis concerned how certain variables affect the level of absorption of development-support instruments by small and medium-sized enterprises. This task was performed with respect to two theoretical models. In the first one, the analysis concerned the influence of a company's developmental orientation and phase of the life cycle on the capacity for using development-support instruments. The results showed that enterprises reporting extensive use of development-support instruments were more often characterized by medium and high orientation to development than entities with low levels of absorption. Thirty-eight percent of companies absorbing a medium and high degree of support were moderately or highly development-oriented. Even more distinct results were obtained in the group of firms declaring the highest usage (5) of development-support instruments. In this category, as many as $73 \%$ were entities displaying a very high developmental orientation.

Similar conclusions may be drawn with reference to the phase of an organization's life cycle. Here, over half of the companies with high support-absorption were in the dynamic phase of the life cycle at the time of the study. Yet clearer results were obtained in the group of companies declaring the highest (5) usage of development-support instruments. In this case, all of the enterprises (100\%) were in the dynamic phases of the life cycle, when high demand for developmentsupport instruments is typical.

On the other hand, in the group of companies with a medium or high orientation to development and at the same time in the dynamic phases of the life cycle ( $13 \%$ of the entire sample), as great a proportion as $38 \%$ declared a high level of absorption of development-support instruments and $48 \%$ a medium level of absorption of them. These results are much higher than those obtained for the whole sample (c. f. Table 2), which indicates the influence on the level of absorption exerted by being oriented to development and the phase of the life cycle. 
This fact is also proved by the relevant regression analysis. Calculations performed with respect to model no. 1 showed that both the orientation to development and the stage of the life cycle significantly affect the level of absorption of development-support instruments by the businesses studied. In this case, the strongest determinant (as measured according to standardized indicators of independent variables) of the scope of use of support instruments was the phase of the company life cycle. The influence of orientation to development was not only estimated at a much lower level, but also at a higher level of significance, which means that the absorption of development-support instruments is primarily linked to dynamic phases of the life cycle. Going through these phases generates considerable demand for developmentsupport instruments.

The reasoning presented above therefore leads to the adoption of hypothesis $\mathrm{H} 1$, whereby the absorption of development-support instruments is significantly determined by the orientation to development and the phase of the life cycle, with the higher level of absorption being characteristic of companies that are highly growth-oriented and in the dynamic phases of the life cycle.

However, the influence of both of the variables mentioned above accounts for only a small proportion (23.6\%) of the variability in absorption, which suggests that there must be other factors determining the scope of use by SMEs of development-support instruments. The analyses presented in the theoretical section showed that companies absorbing support instruments need to harness certain resources and develop specific skills that would allow them to identify, obtain and effectively use these instruments. The relevant resources were knowledge and inter-organizational relations and the skills were operational flexibility and the ability to implement organizational changes. The empirical section of the study consisted in analyzing the influence of these variables on the level of the absorption of development-support instruments by the entities surveyed.

The research results demonstrated that the involvement of both categories of resources, as well as the development of the key skills, increased as the levels of absorption of development-support instruments grew. This shows that the growth of the capacity of the entities surveyed to employ development-support instruments is associated with increasing the involvement of knowledge and inter-organizational relations, as well as with generating the ability to act flexibly and implement changes. A higher level of absorption of support instruments results in a growing demand for the resources identified and requires better development of the said skills. The detailed results of this analysis are given in Table 6.

Table 6. Average levels of involvement of resources and improvement of skills in levels of absorption of support instruments

\begin{tabular}{|c|c|c|c|c|}
\hline \multirow{2}{*}{ Level of absorption } & \multicolumn{4}{|c|}{ Average level of involvement of resources and improvement of skills } \\
\cline { 2 - 5 } & Knowledge & Flexibility & Relations & Implementation of changes \\
\hline Low & 2.11 & 2.11 & 2.12 & 1.98 \\
\hline Medium & 3.03 & 3.01 & 3.11 & 2.81 \\
\hline High & 3.74 & 3.43 & 3.79 & 3.31 \\
\hline
\end{tabular}

Source: Individual compilation based on study results.

This fact is also proved by the relevant regression analysis. Calculations performed with respect to model no. 2 showed that all of the resources and skills identified significantly affect the level of absorption of development-support instruments by the businesses studied. In this case, the strongest and most significant influence on the scope of use of support instruments (measured based on standardized indicators of independent variables) is exerted by knowledge of the availability, terms of acquisition and possible effects of using various development-support instruments. In the sample, the use of development-support instruments is least influenced by the ability of businesses to flexibly adjust to the requirements set by institutions offering support, which need to be met in order to obtain and make use of that support. This factor, though at a very low level of importance $(p<.1)$, also affects absorption.

The arguments set out above lead to the adoption of hypothesis $\mathrm{H} 2$, whereby the absorption of developmentsupport instruments by SMEs is significantly determined by the involvement of resources, namely knowledge and interorganizational relations, and abilities, namely operational flexibility and implementation of organizational changes. Furthermore, the influence of the four variables mentioned above explains the variability of absorption to a high degree (over 50\%), which makes them key (strategic) factors determining the use of development-support instruments by the companies surveyed.

Introducing all of the variables studied to the regression model (Model no. 3) does not materially increase the 
explanatory strength of the variability in support-absorption. In the full model, the level of absorption (measured according to standardized indicators of independent variables) is most affected by knowledge about development-support instruments. The limited influence of flexibility on the level of use of the support instruments should also be noted. This factor no longer has any considerable weight with respect to the response variable under analysis and, when the method of backward elimination for introducing variables is employed, leads to its removal from the optimum model (Model 3a). It seems that in this case, flexibility is compensated by the influence of dynamic phases of the life cycle. This is because operating in periods of dynamic development and growth requires SMEs to display exceptional flexibility, activity and entrepreneurship. Thus, in these stages, flexibility and the capacity to adjust to a turbulent external environment increase - at least in some measure - naturally.

\section{Limitations and Future Research Directions}

Taking into account the individual stages and requirements of the research process (Rubin \& Babbie 2010), certain methodological limitations characterizing the results presented in the paper and the reasoning based on them should be noted. The first problem concerns the relatively small headcount of the sample. In 2012, there were 1.5 million nonfinancial small and medium-sized enterprises in the EU, accounting for 7.6 percent of all non-financial enterprises (Wymenga, Spanikova, Barker, Konings and Canton 2012). Consequently, a study conducted on a sample of 300 entities is hardly representative and generalizations based on it may contain a significant amount of error.

The second problem lies in the subjectivity of respondents' assessments. In the course of the survey, entrepreneurs defined the levels of support absorption in a subjective and rather simplistic manner. Subjective evaluation was also made with reference to the level of knowledge of the possibilities for using these instruments, the development of relationships with business-related institutions, the capacity for flexible reactions to the requirements of the development- support environment and the ability to implement organizational changes based on the support used.

The third problem stems from the employment of simplified scales - based on the idea of the Likert scale - for measuring most of the variables. Some assumptions were made which allowed these measures to be treated as quantitative variables, but the inferences made from them will always be less certain and carry a higher risk of error.

Taking these limitations into account, the research was viewed as a pilot study and the results are to be deemed as identifying preliminary empirical trends that require corroboration in the course of more advanced studies. The lack of scope for broader interpretation of the indicators of independent variables in the regression model, and the impossibility of using the models for forecasting company activity, seem particularly troubling.

To obtain more precise results, plans have been made to continue studies of the issue of the absorption of development-support instruments in the management of SMEs - primarily in the strategic context. To this end, surveys will be conducted on a larger sample of micro-, small and medium-sized businesses in the near future. It is planned to apply comparative multivariate analysis (Johnson \& Wichern 2007; Härdle \& Simar 2012) in the quantitative research, with absorption, knowledge, flexibility, relations and the ability to implement changes being aggregated as diagnostic variables and determined according to the criteria of the Delphi method (Linstone \& Turoff 2002; Hsu \& Sandford 2007; Green, Armstrong \& Graefe 2007). These variables will come in the form of synthetic indicators and will be unified using the classic method in order to homogenize the scope of their variability and employ the method of multiple regression analysis.

It is also planned to supplement quantitative survey research with the results of qualitative research conducted in the form of case studies (Eisenhardt 1989; Baxter \& Jack 2008). At that point, it is intended to study a sample of three model, and three anti-model, micro-, small and medium-sized enterprises in terms of their use of development-support instruments. It is hoped that many of the limitations mentioned above will be overcome in this further research and that the results obtained will provide a range of new and more precise cognitive and applicable conclusions.

\section{Conclusion}

The distinctive features of small and medium-sized enterprises render their ability to make use of external support instruments one of the key factors determining their developmental processes. The basic determinants of the capacity to absorb external support include high orientation to development and dynamic phases of the life cycle, which are conducive to a rise in demand for support instruments. Nevertheless, these factors do not to any large extent explain the ability of SMEs to absorb development-support instruments. This capacity is much more strongly determined by the 
possession of specific resources and by the development of key skills and characteristic of SMEs. These resources include:

knowledge of the availability, terms of acquisition, benefits and possible threats of using various developmentsupport instruments

- relations with the environment, which help in obtaining and using development-support instruments.

The strategic skills determining the use of development-support instruments by SMEs include:

- operational flexibility so that the requirements set by support institutions, which are necessary for obtaining and making use of development-support instruments, can be met

- efficient implementation of developmental changes stimulated by the use of development-support instruments that concern not only the SMEs, but also their social and economic environments.

The results of the empirical studies presented in this paper confirm the adopted premises and make it possible to verify the research hypotheses formulated. Some doubts appeared after introducing all of the identified variables to the regression model and these will require follow-up studies to obtain a more detailed explanation of the influence of strategic factors on the absorption of development-support instruments by SMEs. The quantitative studies will therefore be continued using more advanced and precise measures. Moreover, the results of qualitative research will also be presented which - on the example of models and anti-models of SME management - will allow for a more precise definition of selected aspects of the absorption of support instruments.

\section{References}

Acevedo, G.L., \& Tan, H.W. (Eds.). (2011). Impact Evaluation of Small and Medium Enterprise Programs in Latin America and the Caribbean, Washington, DC: World Bank Publications.

Adamik, A. (2008). Creating of Competitive Advantage Based on Cooperation, Lodz: Technical University of Lodz Press.

Adizes I. (1988). Corporate Lifecycles. How and Why Corporations Grow and What to Do About It, Englewood Cliffs, NJ.: Prentice-Hall. Albassam, B.A. (2012). The New Role of the Nonprofit Sector. Mediterranean Journal of Social Sciences, 3(1), 77-88.

Anderson, A., Li, J-H., Harrison, R., \& Robson, P.J. (2003). The Increasing Role of Small Business in the Chinese Economy. Journal of Small Business Management, 41(3), 310-316.

Ayyagari, M., Beck, T., \& Demirgüç-Kunt, A. (2007). Small and Medium Enterprises Across the Globe. Small Business Economics, 29(4), 415-434.

Baxter, P. \& Jack, S. (2008). Qualitative Case Study Methodology: Study Design and Implementation for Novice Researchers. The Qualitative Report, 13(4), 544-559.

Birch, D. (1981). Who Creates Jobs? Public Interest, 65, 3-14.

Birch, D. (1987). Job Creation in America, How our Smallest Companies Put the Most People to Work, New York, NY: The Free Press.

Bossoutrot, S.K. (2005). Microfinance in Russia: Broadening Access to Finance for Micro and Small Entrepreneurs, Washington, DC: World Bank Publications.

Churchill N., \& Lewis V. (1983). The Five Stages of Small Business Growth. Harvard Business Review, 61(3), 30-50.

Commission Recommendation (2003). 2003/361/EC of 6 May 2003 Concerning the Definition of Small and Medium-Sized Enterprises, Official Journal of the European Union, L 124, 20.5.2003.

Commission Regulation (2004). 364/2004 of 25 February 2004 amending Regulation (EC) No 70/2001 as regards the extension of its scope to include aid for research and development, Official Journal of the European Union, L 63/22, 28.2.2004.

Davidsson P., Achtenhagen L., \& Naldi L. (2010). Small Firm Growth, Hanover, MA.: Now Publishers Inc.

Davidsson, P., Lindmark, L., \& Olofsson, C. (1998). The Extent of Overestimation of Small Firm Job Creation - an Empirical Examination of the Regression Bias. Small Business Economics, 11(1), 87-100.

Dumi A., \& Maliqi, G. (2011). Develop the Enabling Environment for Innovative Entrepreneurship. Mediterranean Journal of Social Sciences, 2(3), 537-542.

Dyson, K. (2012). Small and Medium Sized Enterprises, Spicers European Policy Reports, London: Routledge.

Ebert, R.J., \& Griffin, R.W. (2005). Business Essentials, New York: Pearson Prentice Hall.

Edmiston, K. (2007). The Role of Small and Large Businesses in Economic Development. Economic Review, 92(2), 73-97.

Eisenhardt, K.M. (1989). Building Theories from Case Study Research. The Academy of Management Review, 14(4), 532-550.

Felsenstein, D. \& Schwartz, D. (1993). Constraints to Small Business Development Across the Life Cycle: Some Evidence from Peripheral Areas in Israel. Entrepreneurship \& Regional Development, 5(3), 227-246.

Gilmore, A., Carson, D., \& Grant, K. (2001). SME Marketing in Practice. Marketing Intelligence \& Planning, 19(1), 6-11.

Göb, R., McCollin, Ch., \& Ramalhoto M.F. (2007). Ordinal Methodology in the Analysis of Likert Scales. Qualilty \& Quantity, 41(5), 601626.

Gorman, G.G. \& McCarthy S. (2006). Business Development Support and Knowledge-Based Businesses. Journal of Technology Transfer, 31(1), 131-143.

Grace-Martin, K. (2008). Can Likert Scale Data Ever be Continuous? [Online] Available: http://karengracemartin.articlealley.com/canlikert-scale-data-ever-be-continuous-670606.html (May 9, 2013). 
Green, K.C., Armstrong, J.S., \& Graefe, A. (2007). Methods to Elicit Forecasts from Groups: Delphi and Prediction Markets Compared. Foresight: The International Journal of Applied Forecasting, 8, 17-20.

Greiner L. (1972). Evolution and Revolution as Organizations Grow. Harvard Business Review, 50(4), 37-46.

Gupta, M. \& Cawthorn G. (1996). Managerial Implications of Flexible Manufacturing for SMEs. Elsevier Advanced Technology, Technovation, 16(20), 77-83.

Härdle, W.K., \& Simar, L. (2012). Applied Multivariate Statistical Analysis, Berlin: Springer.

Harvie, Ch., \& Lee, B.C. (Eds.). (2002). The Role of SMEs in National Economies in East Asia, Cheltenham: Edward Elgar Publishing.

Henrekson, M., \& Johansson, D. (2009). Gazelles as Job Creators: a Survey and Interpretation of the Evidence. Small Business Economics, 35(2), 227-244.

Hölzl, W. (2009), Is the R\&D Behaviour of Fast-Growing SMEs Different? Evidence from CIS III Data for 16 Countries. Small Business Economics, 33(1), 59-75.

Hsu, Ch-Ch., \& Sandford, B.A. (2007). The Delphi Technique: Making Sense of Consensus. Practical Assessment, Research \& Evaluation, 12(10), 1-8.

Ionica, O. (2012). The Role of SME Sector in the Post-Socialist Countries' Future. International Journal of Business \& Social Science, $3(9), 173-182$.

Johnson, R.A., \& Wichern, D.W. (2007). Applied Multivariate Statistical Analysis, Englewood Cliffs, NJ: Prentice Hall.

Kaufmann, A., \& Tödtling, F. (2001). Science-Industry Interaction In The Process Of Innovation: The Importance of Boundary-Crossing Between Systems. Research Policy, 30(5), 791-804.

Likert, R. (1932). A Technique for the Measurement of Attitudes. Archives of Psychology, 140, 1-55.

Linstone, H.A. \& Turoff M. (Eds.). (2002). The Delphi Method. Techniques and Applications, Murray Turoff and Harold A. Linstone.

Lubke, G.H., \& Muthen, B.O. (2004). Applying Multigroup Confirmatory Factor Models for Continuous Outcomes to Likert Scale Data Complicates Meaningful Group Comparisons. Structural Equation Modeling, 11(4), 514-534.

Lukács, E. (2005). The Economic Role of SMES in World Economy, Especially in Europe. European Integration Studies, 4(1), 3-12.

Matejun, M. (2013). Instruments Supporting Development in the Life Cycle of Small and Medium-Sized Enterprises. International Journal of Economic Sciences, 2(1), 40-60.

McDonald, J. \& Wiesner, R. (1997). Organizational Change and Enterprise Bargaining in Regional SMEs. In T. Bramble, B. Harley, R. Hall, \& G. Whitehouse (Eds.), Current Research in Industrial Relations, Proceedings of the 11th AIRAANZ Conference, 30 January - 1 February, Brisbane, 485-492.

Nicholls-Nixon, Ch.L. (2005). Rapid Growth and High Performance: The Entrepreneur's "Impossible Dream?" The Academy of Management Executive, 19(1), 77-89.

Ogbo, A., \& Nwachukwu, A.Ch. (2012). The Role of Entrepreneurship in Economic Development: the Nigerian Perspective. European Journal of Business and Management, 4(8), 95-105.

Phelps R., Adams R., \& Bessant J. (2007). Life Cycles of Growing Organizations: A Review with Implications for Knowledge and Learning. International Journal of Management Reviews, 9(1), 1-30.

Qarri, A., Dumi, A., \& Demo, E. (2012). Micro Business Financing System and Development of Credit Lines in Albania. Mediterranean Journal of Social Sciences, 3(1), 33-43.

Rrustemi, V. (2011). Organizational Learning and Knowledge Creation Processes in SMEs. Journal of Knowledge Management, Economics \& Information Technology, 1(6), 168-188.

Rubin, A., \& Babbie, E.R. (2010). Essential Research Methods for Social Work, Belmont, CA.: Cengage Learning.

Smallbone, D., \& Welter, F. (2009). Entrepreneurship and Small Business Development in Post-Socialist Economies, New York, NY.: Routledge.

Storey, D.J. (1994). Understanding the Small Business Sector, London: Routledge.

Storey, D.J., \& Greene, F.J. (2010). Small Business and Entrepreneurship, Essex: Pearson Education Limited.

Torrès, O., \& Julien, P.A. (2005). Specificity and Denaturing of Small Business. International Small Business Journal, 23(4), 355-377.

Volberda, H. (1996). Towards the Flexible Form: How to Remain Vital in Hypercompetitive Environments. Organizational Science, 7(4), 359-374.

Wang D., \& Huang D. (2012). Interpretation of the Government SME Support Policy Changes in South Korean and the Revelation to China. Cross-Cultural Communication, 8(1), 27-32.

Wong, K.Y. \& Aspinwall, E. (2004). Characterizing Knowledge Management in the Small Business Environment. Journal of Knowledge Management, 8(3), 44-61.

Wymenga P., Spanikova V., Barker A., Konings J., \& Canton E. (2012). EU SMEs in 2012: at the Crossroads. Annual Report on Small and Medium-Sized Enterprises in the EU, 2011/12, Rotterdam: Ecorys Nederland BV.

Zeng, S.X., Xie, X.M. \& Tam, C.M. (2010). Relationship Between Cooperation Networks and Innovation Performance of SMEs. Technovation, 30(3), 181-194. 
